\title{
Dynamic Mechanical Properties of Maxillofacial Materials
}

\author{
A. KORAN and R. G. CRAIG \\ Department of Dental Materials, School of Dentistry, University of Michigan, \\ Ann Arbor, Michigan 48104, USA
}

Six maxillofacial materials were evaluated by determining their dynamic properties with use of a Goodyear Vibrotester. The dynamic modulus, internal friction, and dynamic resilience were measured for all materials over a temperature range of -15 to $37 \mathrm{C}$. The dynamic modulus ranged from 11.1 to $124.8 \mathrm{~kg} / \mathrm{cm}^{2}$ and the dynamic resilience varied from 1.1 to $63.5 \%$.

Maxillofacial materials have been neglected in research investigations of dental materials. As a result of the limited market for these products, manufacturers have only nominal interest in their production and marketing. To the thousands of people who suffer from orofacial deformities, however, these materials can represent the difference between a nearly normal life or an existence of fear and disfigurement. Fortunately, more interest is being focused on these materials and the prospects that they will be improved in the future is beginning to appear promising. 1,2

In 1972, Sweeney et $a^{3}$ reported on the results of extensive testing of the physical properties of elastomers that might be suitable for maxillofacial appliances. They stated that, in general, they were looking for materials that simulated the oral tissues and that all available materials had a life expectancy of one year or less. Flexibility was considered by them to be an important re quirement for maxillofacial materials; however, the dynamic properties of the elastomers were not determined.

Lontz, Schweiger, and Burger ${ }^{4}$ reported on the modification of stress-strain profiles of siloxane elastomers. The tensile modulus was used to match the flexibility of the elastomers to that of various tissues of the body such as aorta, tendon, and muscle fibers.

Received for publication July 15, 1974 .

Accepted for publication June 27, 1975.
Again, the dynamic properties of the elas. tomers were not considered.

If the premise is accepted that maxillofacial materials should simulate the oral tissues, then the dynamic nature of these tissues must be considered. The oral tissues are constantly moving and are subjected to a multitude of forces in many directions in both tension and compression. These oral tissues are soft, tough, and quite resilient. Unfortunately, the dynamic properties of the oral tissues have not been determined, although estimates can be made. It is quite possible, however, to measure the dynamic properties of the elastomers as a function of the temperature range over which they are called upon to function. Knowledge of these properties can lend insight into the development of new materials and the evaluation of elastomers that are currently available.

The purpose of this study was to evaluate the dynamic physical properties of the available maxillofacial materials; more specifically, the dynamic modulus, internal friction, and dynamic resilience were determined for six maxillofacial materials that are commercially available. The tests were conducted over a moderate temperature range to simulate service conditions.

\section{Materials and Methods}

Six commercially available products were chosen for evaluation. These could be separated into three basic chemical types: polyvinyl chloride, polyurethane, and silicone (Table 1). The code letter, brand name and manufacturer are also listed.

These products represent most of the elastomers used for maxillofacial applications. The polyvinyl chloride and silicones have been used for some time although the polyurethane is a rather new addition to the armamentarium of the prosthodontist. 
TABLE 1

Maxillofacial Materials

\begin{tabular}{|c|c|c|c|}
\hline Code & Material Class & Brand Name & Manufacturer \\
\hline A & $\begin{array}{l}\text { Plasticized polyvinyl } \\
\text { chloride }\end{array}$ & Prototype III Soft & $\begin{array}{l}\text { Sartomer Resins Inc., } \\
\text { Philadelphia, } \mathrm{Pa}\end{array}$ \\
\hline B & Polyurethane & Dermathane 100 & $\begin{array}{l}\text { Med. Indust. Polymer } \\
\text { Sciences Inc., } \\
\text { Waukesha, Wis }\end{array}$ \\
\hline $\mathrm{C}$ & Heat-cured silicone & MDX 44514 & $\begin{array}{l}\text { Dow Corning Corp. } \\
\text { Midland, Mich }\end{array}$ \\
\hline D & Heat-cured silicone & MDX 44515 & $\begin{array}{l}\text { Dow Corning Corp. } \\
\text { Midland, Mich }\end{array}$ \\
\hline $\mathrm{E}$ & $\begin{array}{l}\text { Autopolymerizing } \\
\text { silicone }\end{array}$ & Silastic 399 & $\begin{array}{l}\text { Dow Corning Corp. } \\
\text { Midland, Mich }\end{array}$ \\
\hline F & $\begin{array}{l}\text { Autopolymerizing } \\
\text { silicone }\end{array}$ & Silastic 382 & $\begin{array}{l}\text { Dow Corning Corp. } \\
\text { Midland, Mich }\end{array}$ \\
\hline
\end{tabular}

A Goodyear Vibrotestera was used for the determination of the dynamic properties of the elastomers (Fig 1). Figure 2 is a schematic sketch which more clearly indicates the essential components of the Vibrotester. This instrument has been used for many years in the rubber industry for the development of new materials and for quality control of commercial products.

The Vibrotester consists of an electrical coil energized by alternating current that

" Goodyear Vibrotester, Goodyear Tire \& Rubber Co., Akron. Ohio. creates a magnetic field. The coil surrounds a yoke of suitable mass and it is possible to vibrate the yoke longitudinally at specific frequencies. The samples to be tested dampen the amplitude of the vibration of the yoke and they function as springs. The system is tuned to resonate at 60 hertz (or other convenient frequencies) by changing the mass of the yoke. The amplitude at resonance and the phase shift between the applied force and the resulting motion are measured optically by the motion of a light attached to the end of the yoke. The am-

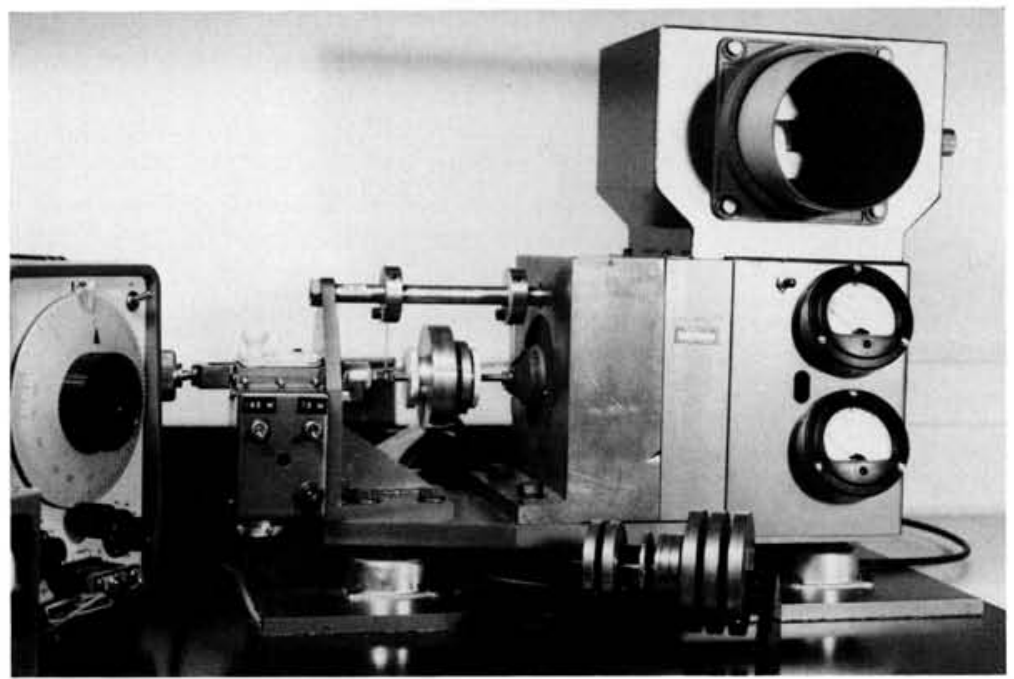

Fig 1.-Goodyear Vibrotester used to determine dynamic properties of elastomers. 


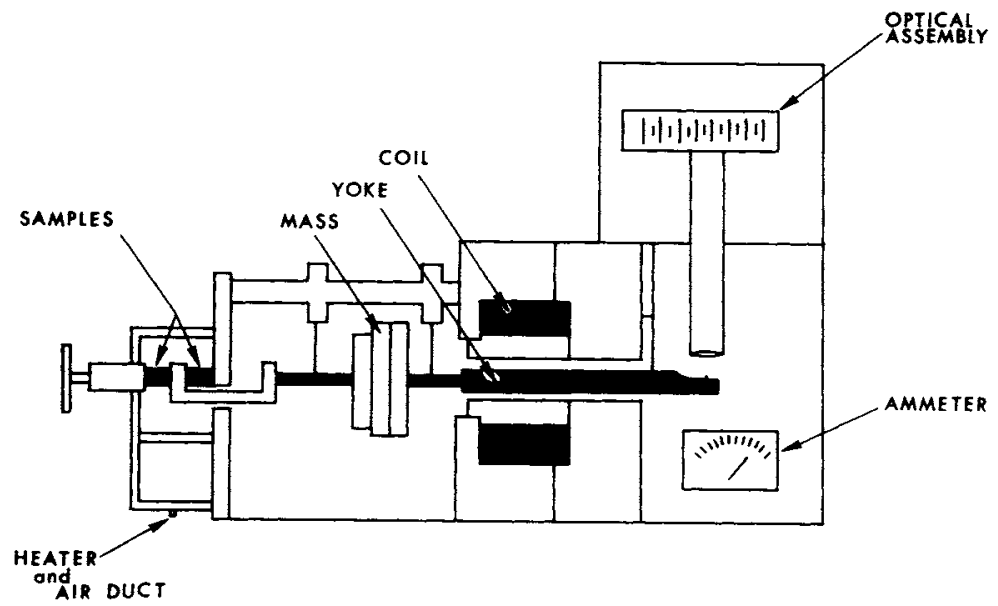

Fig 2.-Schematic diagram of Goodyear Vibrotester.

plitude of the vibration is measured by the width of the light beam on a ground-glass optical assembly shown in Figure 2. The data collected consist of the mass of the yoke which can easily be measured and changed, the frequency of the system at resonance, and the current required to resonate the system at a specific magnitude. This information is used to calculate the dynamic modulus, internal friction, and dynamic resilience as shown in equations 1,2 , and 3 .

$$
\text { Dynamic modulus }=E=m q p^{2}
$$

where $m$ is the mass of yoke in grams; $q$, height $/ 2 \times$ cross-sectional area of specimen; and $p$, angular frequency at resonance in radians per second.

$$
\text { Internal friction }=N=\frac{F q}{p X r e s}
$$

where $F$ is the driving force in dynes; $q$, height $/ 2 \times$ area of specimen; $p$, the angular frequency in radians per second, and Xres, the amplitude at resonance.

$$
\text { Dynamic resilience }=R=100 e^{-2 p N / E}
$$

where $p$ is the angular frequency in radians per second; and $N / E$, the ratio of the internal friction to the dynamic modulus.

It is also possible to calculate the relative heat generation of the specimens, although it has no direct application in the area of maxillofacial materials. The internal friction values are necessary to calculate the dynamic resilience of the specimens.
Samples for the Vibrotester are used in pairs and they are made in a steel mold. The samples are right cylinders one half inch in diameter and one half inch in length.

All materials were used according to the manufacturer's instructions. The plasticized polyvinyl chloride and the heat-cured silicones required no mixing and were vulcanized at temperatures of 175 and $250 \mathrm{C}$, respectively. The autopolymerizing silicones were mixed, placed in the mold under pressure, and allowed to cure at $37 \mathrm{C}$. The polyurethane was processed under pressure at $100 \mathrm{C}$ and allowed to cure for one hour. In all instances, a pressure of 1,000 psi was used during closure of the mold and this pressure produced adequate samples.

A distinct advantage of the Vibrotester is that the dynamic properties can be determined over a wide temperature range. The test chamber may be heated by passing a stream of dry air over electrically heated coils and into the test chamber. The chamber may be cooled by passing the dry air through a copper coil immersed in a Dewar flask filled with dry ice and acetone. By controlling the air flow, it was possible to control the temperature to $\pm 1 / 2 \mathrm{C}$. The following temperatures were used: $-15,0,15,23,30$, and $37 \mathrm{C}$.

For each temperature, three pairs of samples were used for each elastomer. All tests were run from 24 to 48 hours after the samples were made in order to determine the initial dynamic properties. 


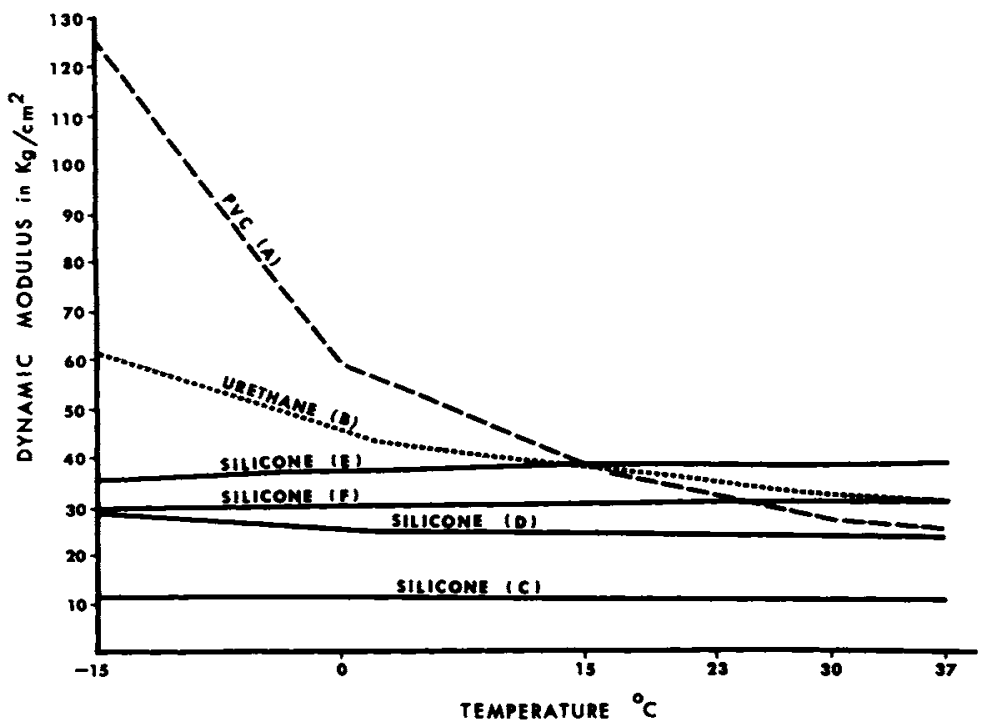

FIg 3.-Dynamic modulus of maxillofacial materials. $P V C$ ( $A$ ) indicates plasticized polyvinyl chloride, Prototype III Soft; $B$, polyurethane, Dermathane $100 ; E$, autopolymerizing silicone, Silastic $399 ; F$, autopolymerizing silicone, Silastic $382 ; D$, heat-cured silicone, $\operatorname{MDX} 44515 ; C$, heat-cured silicone, MDX 44514 .

Means of the three sample pairs were calculated and subjected to statistical analysis. The Scheffe's method was used for comparisons of mean values at each temperature and the test was conducted at a 0.95 level of confidence.

\section{Results}

The results summarizing the dynamic modulus for all six elastomers are shown in Figure 3. From 15 to $37 \mathrm{C}$, five of the six elastomers had a dynamic modulus within a range of 24 to $39 \mathrm{~kg} / \mathrm{cm}^{2}$. Also, within that temperature range the plasticized polyvinyl chloride and polyurethane showed a distinct decrease in the dynamic modulus of 34 and $16 \%$, respectively. The dynamic modulus vs temperature curves flatten out at the higher temperatures with small or insignificant changes taking place as the temperatures increased.

From 15 to $-15 \mathrm{C}$, there was a $226 \%$ increase in the dynamic modulus of the plasticized polyvinyl chloride. The polyurethane showed a less dramatic increase of $63 \%$. These changes in the dynamic modulus occurred over reasonable environmental temperature ranges to which maxillofacial materials could be subjected.
The autopolymerizing and heat-cured silicones displayed stability in the dynamic modulus over the entire temperature range -15 to $37 \mathrm{C}$. The largest change was found with the heat-cured silicone $D$ which had only a $14 \%$ change. The heat-cured silicone C had the lowest dynamic modulus of all materials studied in the specified temperature range, 11.1 to $11.8 \mathrm{~kg} / \mathrm{cm}^{2}$. This product was much softer than any of the other materials and most likely would be limited to very specific clinical applications.

The dynamic resilience values of the various maxillofacial materials are shown in Figure 4. The dynamic resilience is a measure of the energy adsorption characteristics of the elastomers over the temperature range studied.

Both autopolymerizing silicones demonstrated a dynamic resilience that was much higher than the other elastomers. The values ranged from 57.7 to $63.5 \%$ for silicone $E$ and from 56.3 to $60.2 \%$ for silicone $F$.

The heat-cured silicones and the polyurethane showed a more moderate dynamic resilience over a temperature range of 0 to $37 \mathrm{C}$, with values ranging from 16 to $23.7 \%$. The dynamic resilience of plasticized polyvinyl chloride did not approach these values 


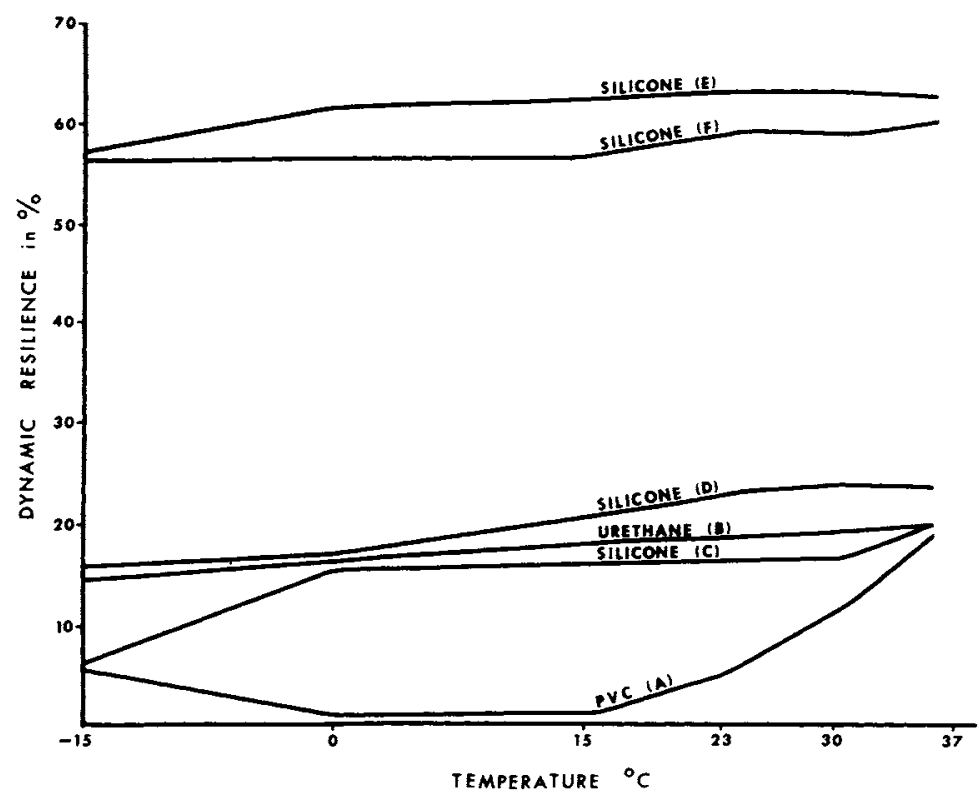

Fic 4.-Dynamic resilience of maxillofacial materials, $P V C$ (A) indicates plasticized polyvinyl chloride, Prototype III Soft; $B$, polyurethane, Dermathane $100 ; E$, autopolymerizing silicone, Silastic $399 ; F$, autopolymerizing silicone, Silastic 382; $D$, heat-cured silicone, MDX 44515; $C$, heat-cured silicone, MDX 44514.

except at $37 \mathrm{C}$. At the lower temperatures, the polyvinyl chloride elastomer showed low values of resilience from 1.1 to $12 \%$.

The numerical values of the dynamic modulus and resilience of the various maxillofacial materials at $37 \mathrm{C}$ are listed in Table 2. The samples are ranked in order of increasing values for dynamic modulus and $d y$ namic resilience. These rankings were done by a one-way analysis of variance of the means and ranking them by the Scheffe method. The standard deviations are also shown to demonstrate the variation of these values. Horizontal lines under the means delineate which means are not statistically different. For the dynamic modulus, the Scheffe interval was $1.96 \mathrm{~kg} / \mathrm{cm}^{2}$ and for the dynamic resilience it was $3.7 \%$.

\section{Discussion}

The evaluation of maxillofacial materials should involve not only the static but the dynamic properties since the stress-strain curves for elastomers are noticeably nonlinear because the strain is time dependent. As a result of time-dependent phenomena

TABLE 2

Dynamic Properties at $37 \mathrm{C}$

\begin{tabular}{|c|c|c|c|c|c|}
\hline \multicolumn{6}{|c|}{ Dynamic Modulus $\left(\mathrm{kg} / \mathrm{cm}^{2}\right)$} \\
\hline Silicone C & Silicone D & PVC A & Silicone $F$ & Polyurethane B & Silicone $\mathrm{E}$ \\
\hline $11.1 \quad(0.83)$ & $24.1(0.10)$ & $25.6(0.96)$ & $30.6(0.46)$ & $31.2(0.52)$ & $39.0 \quad(0.35)$ \\
\hline \multicolumn{6}{|c|}{ Dynamic Resilience $(\%)$} \\
\hline Silicone C & PVC (A) & Polyurethane B & Silicone D & Silicone $\mathbf{F}$ & Silicone E \\
\hline $18.9(0.23)$ & $19.6(0.61)$ & $19.9 \quad(0.92)$ & $23.2(0.64)$ & $60.2(2.3)$ & $62.7(0.93)$ \\
\hline
\end{tabular}

Note: Mean values are underlined when there is no statistical difference; $S D$ in parenthesis. See Table 1 for identification of maxillofacial materials. 
like creep, rubber and viscoelastic materials in general exhibit physical properties that are time dependent. The bulk modulus is defined as a ratio of stress to strain in the elastic region. However, in static testing, an apparent modulus is obtained because of the time dependence of strain and the strain rate must be specified. The time dependence of the stress-strain curves lends importance to measurement of the dynamic properties of elastomers. ${ }^{5}$ The dynamic modulus is the ratio of the stress to strain at a fixed percent compression provided by the Vibrotester $(8 \%)$.

Cyclic stretching or compression of rubber results in familiar hysteretic loops. The energy irreversibly lost is enclosed within the loop. This lost energy appears mainly as heat and results in the concept of internal friction of rubber which may be compared with the viscosity of liquids.

The ratio of the energy returned to the energy expended is termed the dynamic resilience of rubber. It is of special importance to materials that function in a dynamic manner and that may be subjected to sudden en. ergy inputs.

The plasticized polyvinyl chloride had dynamic properties that were seriously affected by temperatures lower than room temperature. These changes are a distinct disadvantage for clinical applications since at lower temperatures the plasticized polyvinyl chloride would be much stiffer than the surrounding soft tissues. The polyurethane also demonstrated this temperature dependence of dynamic properties, but to a lesser extent.

The silicones had dynamic properties that were quite stable over the temperature range of -15 to $37 \mathrm{C}$. One of the heat-cured silicones was considerably softer than all other materials tested. The autopolymerizing silicones were considerably more resilient than any of the other materials. The stability over this temperature range could be a distinct advantage for service as a maxillofacial material.

In future studies, the dynamic properties will be determined over a wider temperature range to include all temperature extremes expected under service conditions. The effect of aging on the dynamic properties of maxillofacial materials must also be determined to evaluate the service life of these materials.

\section{Conclusions}

The Goodyear Vibrotester is well suited for dynamic testing of elastomers used as maxillofacial materials. It uses a forced vibration method for determining the dynamic properties. Sample preparation is convenient and the testing is nondestructive.

In this study, the plasticized polyvinyl chloride material showed the greatest change in the dynamic modulus from $124.8 \mathrm{~kg} / \mathrm{cm}^{2}$ at $-15 \mathrm{C}$ to $25.2 \mathrm{~kg} / \mathrm{cm}^{2}$ at $37 \mathrm{C}$. The polyurethane material was affected by varying temperatures, but to a lesser extent with a dynamic modulus of $61.5 \mathrm{~kg} / \mathrm{cm}^{2}$ at $-15 \mathrm{C}$ and $31.2 \mathrm{~kg} / \mathrm{cm}^{2}$ at $37 \mathrm{C}$. The silicones showed little or no change over this same temperature range with moduli of different materials varying from 11.1 to $39.3 \mathrm{~kg} / \mathrm{cm}^{2}$.

The lowest values for dynamic resilience were $1.1 \%$ at $0 \mathrm{C}$ for the polyvinyl chloride and $5.1 \%$ at $-15 \mathrm{C}$ for the heat-cured silicone MDX 44514. The highest values for the dynamic resilience were found at $37 \mathrm{C}$ for the two autopolymerizing silicones at 60.2 and $62.7 \%$, respectively.

The laboratory evaluation of elastomers for maxillofacial applications should include not only the static but dynamic properties since the stress-strain curve is noticeably nonlinear for these materials. These tests should be conducted over a temperature range to reflect the service conditions of the materials.

\section{References}

I. Castleberry, D.J.: Dental Biomaterials, Research Priorities, WAchtel, L.W. (ed), Washington, DG: Department of Health, Education and Welfare Publication No. 74-548, August 7-8, 1963, pp 255-262.

2. Chalian, V.A.; Drane, J.B.; and Standish, S.N.: Maxillofacial Prosthodontics-Multidisciplinary Practice, Baltimore: Williams \& Wilkins Co., 1972, p 456.

3. SWeeney, W.T.; Fisher, T.E.; Castleberry, D.J.; and Cowperthwarte, G.F.: Evaluation of Improved Maxillofacial Prosthetic Materials, J Prosthet Dent 27: 297-305, 1972.

4. Lontz, J.F.; SchWeiger, J.W.; and Burger, A.W.: Modifying Stress-Stain Profiles of Polysiloxane Elastomers for Improved Maxillofacial Conformity, J Dent Res 53 (Special Issue) : Abstract No. 890, 1974.

5. Gehman, S.D.: Dynamic Properties of Elastomers, Rubber Chem Tech 30: 1202-1250, 1957. 